\title{
Iconografia, História, Antigüidade grega II: a cidade das imagens
}

\author{
Marcos Alvito Pereira de Souza \\ IFCH/Universidade Federal Fluminense
}

Entrer en imagerie est peut-être plus facile que d'en sortir.

(C. Bérard, in La cité des images. Religion et société dans la Grèce antique. Paris/Lausanne, F. Nathan/ELP, 1984, p.162)

A década de 1980 assistiu a uma verdadeira explosão de estudos sobre a iconografia grega antiga, motivo de inúmeros simpósios ${ }^{1}$. Refletindo este espírito, dois dos centros mais importantes neste tipo de pesquisa, o Institut $d$ 'archéologie et $d$ 'histoire ancienne - de Lausanne, e o Centre de recherches comparées sur les sociétés ańciennes - de Paris, juntaram forças para produzir uma obra coletiva em 1984. La cité des images é o resultado deste empreendimento inter-institucional e interdisciplinar, pois contou com a colaboração de arqueólogos, historiadores e filólogos. O livro, como explica Jean-Pierre Vernant no prefácio, é voltado para o grande público e tem a "ambição de permitir o acesso a este universo humano hoje desaparecido" (p.4), menção às inúmeras dificuldades documentais enfrentadas pelos helenistas.

Quanto à temática, centrou-se naquilo que Vernant chama de "temas antropológicos maiores": "o jovem, o guerreiro, a mulher, os animais selvagens e domésticos nas suas relações com os homens, o erotismo, as festas religiosas, - universo dionisíaco" (p.5). Através de séries de imagens, os autores procuraram iluminar "o imaginário social da Atenas clássica".

Já de saída, afirmam-se princípios metodológicos; estas séries de imagens constituem "uma codificação do real segundo as modalidades que the são próprias". Descartam-se, deste modo, dois tipos de leituras deformantes: a visão das cenas pintadas como mera ilustração de discursos (orais ou escritos) ou como "a pura reprodução fołográlica do real".

1. Méthodologie Iconographique. Actes du Colloque de Strasbourg, 2728 abril de 1979 , Strasbourg, AECR, 1981. Actes du Colloque sur les problémes de l'image dans le monde méditerranéen classique. Château de Lourmarin en Provence, $2-3$ setembro de 1982, Roma, Giorgio Bretschneider. Image et céramique grecque, Actes du Colloque de Rouen, 25-6 novembro de 1982, Rouen, Publications de l'Université n.96, 1983. Images et société en Gréce ancienne - l'iconographie comme mé- 
thode d'analyse. Actes du Colloque international, Lausanne 8-11. fevereiro de 1984. Ancient Greek and Related Pottery, Proceedings of the International Vase Symposium in Amsterdam, 12-5 abril de 1984

2. Ver a crítica a esta "marginalização da cultura material" em Meneses (1984).

3. "Eros en Chasse", pp.67-84.
O primeiro capítulo funciona apenas como um breve reconhecimento do suporte material das imagens, isto é : os vasos de cerâmica, suas formas e funções. Sobre a produção destes objetos de uso múltiplo e bastante popular, pouco se diz. Salienta-se, em apenas um parágrafo, a dificuldade de conhecer o funcionamento dos "ateliers" de ceramistas e pintores. Acerca do circuito de comercialização e consumo, os autores nada observam. Esłe silêncio é significativo e bastante típico da corrente teórica que fundamenta a obra².

"Entrer en imagerie" é o sugestivo título do segundo capítulo. Aqui, trata-se sobretudo de uma demonstração metodológica. Como iá dissera J.P.Vernant na introdução, as imagens são vistas como parte de um sistema a decifrar. O sentido, como na linguística estrutural, surge a partir das relações que os elementos básicos, ou signos, estabelecem entre si. Toda cena é "uma combinação complexa de elementos figurativos", e o significado da cena emerge gradativamente "da análise das regras que estruturam esta combinação" (p.21).

Exemplifiquemos: o significado de determinados elementos figurativos (para usar a terminologia dos autores), como a coluna ou o pedestal é dado a partir da combinação existente em cada cena. Uma coluna cercada de jovens flautistas e de cantores sugere um pórtico ou uma cena de teatro, enquanto a mesma coluna combinada com um altar e cenas de culto indica certamente um templo. De qualquer forma, a coluna aparece sobretudo para delimitar um espaço preciso, seja ele privado ou público, laico ou sagrado. Há "um repertório de unidades formais mínimas", comum aos artesãos e aos seus fregueses. As variações deste repertório emprestam significado às cenas (p.23). O mais importante, sobretudo, é a percepção de que não há, por parte dos artistas, uma "reprodução quase fotográfica da vida cotidiana" (p.31), mas sim um sistema arbitrário, um código com o qual temos de nos familiarizar para compreender a mensagem dos vasos pintados.

Esta proposta metodológica é comum ao conjunto de especialistas, fornecendo uma coerência singular ao livro. A análise mais detida de um capítulo será suficiente, portanto, para fundamentar nossos comentários, nos quais, sempre que possível, faremos menção a outros artigos.

Alain Schnapp escreve sobre o universo erótico do homossexualismo masculino (o autor não usa o termo pederastia) ${ }^{3}$. Demonstra, inicialmente, a associação existente entre a caça da lebre e os valores da "juventude dourada" ateniense. As representações da caçada desprezam completamente as armadiThas que, sabemos graças aos conselhos práticos de Xenofonte, eram muito utilizadas. A imagística não reproduz a caça à lebre tal qual ela ocorria nos bosques da Ática, ela produz uma espécie de discurso em imagens acerca da educação dos jovens. Correr atrás do animal para capturá-lo, fundindo-se à paisagem, proporciona ao efebo uma iniciação, um ritual de passagem ao mundo adulto. A apropriação da caça por parte da imagística erótica é um passo natural, já que as relações estabeleciam-se sobretudo entre homens maduros e jovens rapazes. São, repectivamente, "erasta" e "erômena", ou, numa tradução aproximativa, "amante" e "amado", são associados ao caçador e à sua presa; muitas vezes simbolizados pelo cão e pela lebre. A caça, como 
seria de se esperar, não é jamais representada no momento do seu consumo como alimento, mas é sempre exibida como troféu. Esta associação, característica dos vasos de figuras negras do período arcaico fica perfeitamente clara em um lécito com três faixas horizontais. De cima para baixo, temos a corte homossexual, cenas de equitação com jovens rapazes e, por fim, um cão perseguindo a lebre. É todo um gênero de vida, característico dos nobres atenienses, que é representado aqui.

Nas imagens do século $V$ opera-se uma transformação, uma ruptura flagrante. As cenas, antes tão diretas em sua simbologia, revestem-se de uma maior sutileza. Os caçadores, antes quase anônimos, começam a ser identificáveis por detalhes, músculos e, sobretudo, por suas fisionomias. Há uma maior caracterização "psicológica", ocorre uma "interiorização". A lebre, antes animal de caça, aparece agora como uma companheira da sedução. A esta mudança, corresponde uma erótica de aproximações e esquivas, sugestivas, em que a lebre é domesticada; ao contrário da agressão erótica característica das cenas do século VI, simbolizada pela caça.

Este é apenas um pequeno exemplo das possibilidades do método que, à revelia dos autores, poderíamos batizar de semiótico-antropológico. A maestria com que o autor mergutha nos "elementos figurativos" e no "código" é surpreendente. Os outros artigos, todavia, não são menos elogiáveis neste aspecto. Claude Bérard, por exemplo, escreve um artigo importante sobre as mulheres atenienses ${ }^{4}$. Os três últimos trabalhos contribuem de maneira significativa para o entendimento dos rituais dionisíacos e de seus elementos principais; os sátiros, as mênades, as máscaras, o tirso5. Este livro representa, sem dúvida, o coroamento de uma longa trajetória.

Durante muito tempo, o estudo da iconografia cerâmica esteve restrito àquilo que chamaremos, mui genericamente, de "arqueologia tradicional". Isto é, o estudo das imagens pintadas nos vasos tinha por único fim a descrição das cenas representadas e a identificação dos atores. Séries colossais, às vezes com muitas centenas de vasos, eram apenas datadas e catalogadas tematicamente de maneira insipida ${ }^{6}$. Não se pense, todavia, que estamos desprezando a crucial contribuição destes estudos para a cronologia ${ }^{7}$. Podemos chamar este estágio de fase descritiva dos estudos iconográficos.

Nas décadas de 60 e 70 deste século, todavia, começa a haver tentativas de estabelecer relações entre as cenas representadas nos vasos e conjunturas políticas. Em 1963, Anne Bovon publica um artigo sobre os guerreiros persas nos vasos atenienses da primeira metade do século $V$ a.C. . A despeito do valor inestimável deste trabalho, que procura responder a uma questão, tentando inclusive estabelecer um diálogo entre a iconografia e as fontes escritas, há críticas a fazer do ponto de vista metodológico. A autora parece ainda presa aos esquemas descritivos da História da Arte, privilegiando a análise das vestimentas e do armamento. $\bigcirc$ significado das imagens é pouco explorado.

Na década de 1970, John Boardman (1972 e 1975) inicia uma série de artigos que vão causar uma acerba polêmica. Tenta relacionar as imagens de Héracles à tirania de Pisístrato e dos seus filhos em Atenas. Boardman teve seguidores, como R.Glynn; mas este tipo de análise, em geral, e o estudo
4. "L'ordre des femmes", pp. 85104

5. Capítulo VIII: Durand J.L., Frontisi-Ducroux, F. \& Lissarague, F., "L'entre deux vins", pp.117-126; capítulo IX: Berard, C. \& Bron, C.," Le jeu du satyre", pp. 127-146; capítulo X: Frontisi-Ducroux, F., "Au miroir du masque", pp.147-160.

6. D.H. Bothmer (1957) Talvez seja o exemplo mais impressionante empreende uma classificação tão colonial quanto insípida de centenas de documentos entre vasos, bronzes e esculturas, sem jamais fazer uma pergunta sequer ao seu riquíssimo material.

7. Para um bom resumo deste aspecto, ver Sarian (1984). 
8. Para uma posição contrária a esta, veja-se o excelente artigo de Bazant (1984).

9. O termo "ideológico", aliás, aparece apenas uma vez em mais de 160 páginas! acerca de Héracles, em particular, foram esmagados pelas críticas : De fato, as relações estabelecidas por John Boardman parecem ter (Cook 1987, Bazant 1982) uma fundamentação frágil e por demais arbitrária em termos iconográficos. É um exemplo daquilo que podemos qualificar de análise ingênua ou subjetiva. Não se propõe uma metodologia específica para a leitura das imagens, cuja interpretação fica então ao sabor das interpretações individuais.

La cité des images constitui um claro avanço do ponto de vista metodológico. Ao invés de simplesmente descrever "cientificamente", ou de tentar "interpretar" subjetivamente, as imagens são submetidas a um procedimento semiótico que busca compreender, antes de tudo, o código através do qual elas assumem um significado. A leitura baseia-se na busca de oposições binárias, à maneira do estruturalismo, centrando seu foco sobre temas antropológicos. Toda opção metodológica, entretanto, tem seus limites.

Poderíamos dizer, sem medo de errar, que a principal lacuna destes estudos é a falta de princípios explicativos. Em outras palavras; não basta, por exemplo, constatar uma mudança na imagística erótica, é preciso explicá-la. É patente em toda a obra a recusa em estabelecer ligaçōes entre este imaginário e as mudanças históricas sofridas pela sociedade ateniense. Leia-se, a este respeito, a seguinte passagem do capítulo IV ("Boucherie sacrificielle et chasses initiatiques") (p.63):

"No começo do século $V$, a caça montada praticamente desaparece da pintura dos vasos. Viu-se nisto uma das conseqüências políticas da instauração da cidade democrática, o desinteresse pelo gênero de vida nobre encarnado pelos jovens cavaleiros. Na verdade, a rarefação das cenas de caça montada é sobretudo o reflexo de um gosto novo: aquele das representações individuais, dos valores heróicos que se encarnam melhor na caça solitária do que nas caças coletivas e anônimas."

Rejeita-se a explicação política ${ }^{8}$ sem por nada em seu lugar, apenas um floreio tautológico: a mudança ocorre por surgir um gosto novo... Mas por que mudam os "gostos"?", podemos perguntar. Se é que devemos utilizar termo tão impreciso para uma representação carregada de conteúdo ideológico 9 . Em um dos poucos artigos do livro a preocupar-se com a dimensão diacrônica, ela fica totalmente à deriva, sem explicação. No artigo dedicado às mulheres atenienses, percebe-se um corte na representação do luto. No século VI a.C., havia o que o autor chama de "imagística precisa e realista, essencialmente descritiva" (p.101). Já no século $V$, predominam as cenas "mais simbólicas". Qual a explicação? Segundo C. Bérard, "as mentalidades mudaram e as preocupações espiriłuais anunciam uma nova era". O que mais nos chama a atenção nesta frase é a indefinição tipicamente estruturalista: as mentalidades "mudam", tão simplesmente.

artigo que acabamos de citar, todavia, é original em um sentido, explora melhor as zonas de sombra das fontes escritas, como a vida das mutheres, servindo de contraponto às esparsas afirmativas paradigmáticas de alguns autores como Xenofonte, com as quais os historiadores costumam contentar-se. $\bigcirc$ capítulo VII ("Fêtes et mystères") também ilumina uma lacuna preciosa, na parte relativa aos mistérios de Elêusis, cujos únicos textos de que dis- 
pomos provêm dos seus detratores cristãos. Alguns artigos do livro, como o já mencionado capítulo quatro, estabelecem relações já antes exploradas como a existente entre o sacrifício e a caça (Sobre o tema, ver Vidal-Naquet 1988). De uma maneira geral, parece haver uma transposição às fontes iconográficas (muito bem feita saliente-se), dos métodos da chamada psicologia histórica de Jean-Pierre Vernant, Pierre Vidal-Naquet e outros ${ }^{10}$.

Na verdade, do ponto de vista metodológico o livro é exemplar. Suas falhas situam-se no plano teórico. $\bigcirc$ passeio por entre as imagens é magnífico. Diríamos que haveria necessidade de incorporar também a sociologia e, sobretudo, a história, às brithantes análises empreendidas nesta obra ${ }^{11}$. Sair das imagens, admite Claude Bérard no posfácio, é mais difícil do que entrar.

\section{BIBLIOGRAFIA}

Actes du Colloque sur les problèmes de l'image dans le monde méditerranéen 1982

classique. Château de Lourmarin en Provence (2-3 septembre 1982). Roma, Giorgio Bretschneider.

Ancient Greek and related pottery. Proceedings of the International Vase 1984 Symposium in Amsterdam (12-15 april 1984).

BAZANT, J.. Eirene, 18:21.

1982

BAZANT, J., Les vases athéniens et les réformes démocratiques. In: Images et 1984 sociéte en Gréce ancienne: 33-40.

BOARDMAN, J.. Herakles, Peisistratos and sons. Revue Archéologique, 1:571972 72.

BOARDMAN, J.. Herakles, Peisistratos and Eleusis. Journal of Hellenic Studies, 1975 95:1-12.

BOTHMER, D.H.. Von Amazons in Greek Art. Oxford, Clarendon Press. 1957

BOVON, Anne. Une représentation des guerriers perses et la notion de barbare dans la première moitié du Vè. siècle. Bulletin de Correspondance Hellénique, 87:579-602.

CARDOSO, Ciro F.S. Semiótica, História e classes sociais. In: Ensaios raciona1988
10. A importância do sacrifício, como elemento que diferencia os homens dos deuses e dos animais é um tema recorrente na obra de Jean-Pierre Vernant. Veja-se, por exemplo: "Entre bêtes et dieux" (Vernant 1988).E Pierre Vidal-Naquet, entretanto, quem inaugura a aplicação do método da psicologia histórica na análise de imagens em "Sobre um vaso do Museu de Siracusa"(VidalNaquet 1988).

1 1. Ciro Cardoso (1988:92) salienta que o inverso também é verdadeiro: "As análises históricas que usam conceitos e pontos de vista semióticos são ainda raras. $\mathrm{Na}$ sua maioria, não foram elaboradas por historiadores. Ao se interessarem pelo que para eles seria um campo novo de pesquisas, os profissionais da História não somente enriqueceriam o seu arsenal teórico e metodológico, como poderiam contribuir utilmente para o progresso da própria semiótica, já que um dos seus defeitos mais correntes é a tendência ao formalismo a-histórico." 
COOK, R.M.. Post and Pisistratan Propaganda. Journal of Hellenic Studies, 1987 107:167-9.

GLYNN, R.. Heracles, Hereus and Triton: a study of iconography in 6th-century 1981 Athens. American Journal of Archeology, 85:121-132.

Image et céramique grecque.Actes du Colloque de Rouen (25-6 septembre 1983 1982). Rouen, Publications de L'Université.

Images et société en Grèce ancienne. L'iconograpbie comme métbode 1987 d'analyse. Actes du Colloque International de Lausanne (8-11 février 1984).

MENESES, Ulpiano Bezerra de. A cultura material no estudo das sociedades anti1984 gas. In: Anais do I Simpósio de História Antiga e Medieval. João Pessoa, UFPb:34-42.

Méthodologie iconographique. Actes du Coloque de Strasbourg (27-28 avril 1981 1979). Strasbourg, AECR.

SARIAN, H.. A cerâmica como documento arqueológico. Revista de Pré1984 bistória, 6:196-204.

VERNANT, J.-P.. Entre bêtes et dieux. In: Mythe et société en Grèce ancienne. 1988 Paris, La Découverte: 141-176.

VIDAL-NAQUE, P.. Caça e sacrifício na Oréstia de Ésquilo. In: Mito e tragédia na 1988 Grécia antiga. São Paulo, Brasiliense: 139-164.

VIDAL-NAQUET, P.. Sobre um vaso do museu de Siracusa. In: Mito e tragédia 1988 na Grécia antiga, apêndice. 